\title{
Prescribing for frail older people
}

\section{Sarah N Hilmer \\ Head \\ Department of Clinical \\ Pharmacology' \\ Senior staff specialist \\ Aged Care \\ Conjoint professor \\ Geriatric Pharmacology² \\ Danijela Gnjidic \\ Lecturer \\ Faculty of Pharmacy² \\ ${ }^{1}$ Royal North Shore Hospital \\ ${ }^{2}$ University of Sydney and \\ Kolling Institute \\ Sydney}

\section{Keywords}

care of aged, deprescribing frail elderly

Aust Prescr 2017:40:174-8 https://doi.org/10.18773/ austprescr.2017.055

\section{SUMMARY}

Frailty is associated with greater exposure to polypharmacy and medicines with anticholinergic and sedative effects, which may increase the risk of adverse outcomes including falls.

People who are frail experience a higher incidence and severity of adverse drug events because of their medicine use and potential changes in pharmacokinetics and pharmacodynamics.

Prescribing for these patients requires constant vigilance and review, considering the impact of every medicine, as well as overall drug load, comorbidities, function and goals of care.

\section{Introduction}

Frailty is a multifactorial syndrome associated with functional impairment and increased susceptibility to disease, disability and mortality and can occur at any age. The clinical definition describes frailty as 'a state of vulnerability to poor resolution of homeostasis following a stress and is a consequence of cumulative decline in multiple physiological systems over a lifespan'?

Although at present, there is no universal way to identify patients with frailty in clinical practice, the two most common approaches used in research are:1

- the phenotype model - frailty defined as the presence of at least three criteria including exhaustion, weakness, unintentional weight loss, slow walking, low physical activity

- frailty indices - accumulation of medical, functional or social deficits.

The prevalence of frailty defined using the phenotype criteria is $9.9 \%$ across studies conducted in community-dwelling older adults. Frailty increases with age $-15.7 \%$ of adults aged $80-84$ years were identified as frail compared with $26.1 \%$ of those aged 85 years and over. ${ }^{2}$ Frailty is very common in Australian acute geriatric medicine inpatients (approximately $90 \%)^{3}$ and in residents of aged-care facilities (approximately 40\%, depending on country studied and scale used). ${ }^{4}$ Frailty is a dynamic state and people can move in and out of it.

\section{Medicine use in frail people}

There is a lack of guidelines to inform appropriate prescribing for frail older adults. They tend to receive more drugs than robust older adults. In community-dwelling older men, polypharmacy ( $\geq 5$ drugs) was reported in $64.7 \%$ of frail men compared with $27.2 \%$ of robust men. ${ }^{5}$ Using the
Drug Burden Index, which is associated with functional impairment in older people, exposure to anticholinergic and sedative medicines was reported in $45.5 \%$ of frail men compared with $20.1 \%$ of robust men. Preventative drugs such as statins are used less often by frail men than by robust men (7.6\% vs $10.4 \%)^{6}$

In acute care, frail patients use significantly more medicines overall compared with other patients (frail $9.8 \pm 4.3$ vs robust $4.4 \pm 3.3$ ), and more medicines that increase the risk of falls (frail $3.4 \pm 2.2$ vs robust $1.6 \pm 1.5){ }^{7}$ This was also observed in a national sample of inpatients, with higher frailty indices seen in patients with polypharmacy and hyperpolypharmacy ( $\geq 10$ drugs). ${ }^{8}$

\section{Impact of frailty on pharmacokinetics and pharmacodynamics}

Evidence of the impact of frailty on drug disposition and effects is very limited. Animal models of frailty are only just starting to emerge, which may shed some light on the impact of frailty on pharmacokinetics and pharmacodynamics. ${ }^{9}$

Applying the limited evidence on the clinical pharmacology of frailty is challenged by different definitions of frailty in trials. For example, many studies use living in a nursing home as a frailty surrogate, although not all nursing home residents are frail when measured by objective measures. Also, studies are often underpowered because of the difficulty recruiting and sampling from frail older people and because this population has increased inter-individual variability.

The physiological changes of frailty are likely to impact on pharmacokinetics and pharmacodynamics. These are outlined in Table 1, along with any evidence available. ${ }^{7,10-17}$ 
Table 1 Impact of frailty on pharmacokinetics and pharmacodynamics

\begin{tabular}{|c|c|c|c|}
\hline Pharmacology & Physiological changes with frailty & Hypothesised impact of frailty & Data comparing frail and robust older people \\
\hline Absorption & $\begin{array}{l}\text { Slowed gastric motility and reduced } \\
\text { hepatic metabolism }\end{array}$ & $\begin{array}{l}\text { Delayed absorption and } \\
\text { reduced bioavailability of drugs } \\
\text { administered orally }\end{array}$ & - \\
\hline \multirow[t]{2}{*}{ Distribution } & Sarcopenia and relative adiposity & $\begin{array}{l}\text { Reduced volume of distribution } \\
\text { of water-soluble drugs and } \\
\text { increased volume of distribution } \\
\text { of fat-soluble drugs }\end{array}$ & \multirow[t]{2}{*}{$\begin{array}{l}\text { Volume of distribution of gentamicin not } \\
\text { significantly reduced in frailty*10 }\end{array}$} \\
\hline & Reduced plasma albumin & $\begin{array}{l}\text { Decreased protein binding of } \\
\text { acidic drugs }\end{array}$ & \\
\hline \multirow[t]{4}{*}{ Metabolism } & \multirow[t]{4}{*}{$\begin{array}{l}\text { Reduced hepatic volume and } \\
\text { blood flow }\end{array}$} & \multirow{4}{*}{$\begin{array}{l}\text { No consistent effects on phase I } \\
\text { clearance } \\
\text { Reduced phase II clearance }\end{array}$} & \multirow{4}{*}{$\begin{array}{l}\text { No independent effect of frailty on } \\
\text { erythromycin breath test (measures CYP3A4 } \\
\text { and P-glycoprotein)*11 } \\
\text { Aspirin esterase activity reduced in plasma }{ }^{12} \\
\text { but not in liver in frailty }{ }^{13} \\
\text { Reduced paracetamol clearance in frailty }{ }^{14}\end{array}$} \\
\hline & & & \\
\hline & & & \\
\hline & & & \\
\hline Excretion & Glomerular filtration rate reduced & Reduced renal drug clearance & Reduced gentamicin clearance in frailty*10,15 \\
\hline \multirow[t]{4}{*}{ Pharmacodynamics } & \multirow{2}{*}{$\begin{array}{l}\text { Reduced resilience to external } \\
\text { stressors }\end{array}$} & \multirow{4}{*}{$\begin{array}{l}\text { Exaggerated or reduced drug } \\
\text { effects }\end{array}$} & Increased sedation with metoclopramide ${ }^{16}$ \\
\hline & & & Increased susceptibility to falls with drugs \\
\hline & \multirow{2}{*}{$\begin{array}{l}\text { May be some reduced receptor } \\
\text { function in presence of chronic } \\
\text { inflammation }\end{array}$} & & acting on the CNS and cardiovascular system*7 \\
\hline & & & $\begin{array}{l}\text { May be reduced response of platelet } \\
\text { aggregation to aspirin in frailty* }{ }^{17}\end{array}$ \\
\hline
\end{tabular}

* Study used an objective measure of frailty. CYP cytochrome P450 CNS central nervous system

\section{Increased risk of adverse effects}

People who are frail are more likely to experience adverse drug events because of their patterns of drug use and, potentially, changes in pharmacokinetics and pharmacodynamics. Also they are more susceptible to the effects of adverse drug reactions because of reduced resilience. Patients with a higher frailty index score are twice as likely to have at least one potentially inappropriate medicine prescribed. They are also more likely to experience an adverse drug reaction compared to those below the frailty threshold. ${ }^{18}$

Recent evidence suggests that increasing medication load is associated with transitioning from the pre-frail to frail status and subsequent death. Each additional drug was associated with a $22 \%$ greater risk of death in men who were initially defined as robust. ${ }^{19}$ Pharmacoepidemiological studies on the effects of specific drug classes, such as ACE inhibitors ${ }^{20}$ or statins,,$^{21}$ on incident frailty have not found significant associations.

\section{Results from clinical trials}

Trial results observed in the general population cannot necessarily be extrapolated to the frail population. Studies of the impact of frailty on the effects of medicines show varying results (see Table 2). ${ }^{6-8,22-25}$ The observational studies highlight the effects of polypharmacy, the use of drugs that increase the risk of falls, and drugs recommended by guidelines for secondary prevention of cardiovascular disease. They suggest that frail older people are more susceptible than non-frail to adverse outcomes, such as falls, institutionalisation and death with drug use.

There are also secondary analyses of randomised controlled trials that examine the impact of frailty on different treatment outcomes. These suggest that with antihypertensive treatment, frail participants may get similar reductions in cardiovascular outcomes and mortality compared to non-frail participants.

Recent debate has focused on whether frailty should be considered when prescribing antihypertensives to older adults. The Hypertension in the Very Elderly Trial (HYVET) suggests benefit with antihypertensive therapy irrespective of frailty status. ${ }^{25}$ In the Systolic Blood Pressure Intervention Trial (SPRINT) of adults aged 75 years or older, treating to a systolic blood pressure target of less than $120 \mathrm{mmHg}$ compared with a target of less than $140 \mathrm{mmHg}$ resulted in significantly lower rates of fatal and nonfatal major cardiovascular events and all-cause mortality. ${ }^{24}$ Frailty did not appear to modify this relationship, although the trial was not powered to assess this. 
Table 2 Medication outcomes in older people stratified by frailty status

\begin{tabular}{|c|c|c|c|}
\hline Study & Participants (number, mean age) & Frailty definition & Outcomes \\
\hline Peeters et al. $2016 * 22$ & $\begin{array}{l}\text { Community-dwelling women } \\
\text { with ischaemic heart disease } \\
\text { and using at least one guideline- } \\
\text { recommended drug } \\
\text { ( } n=885,82.7 \text { years) }\end{array}$ & $\begin{array}{l}\text { 'Frail scale' i.e. at least } 3 \text { of } \\
\text { - }>5 \% \text { weight loss over } 3 \text { years } \\
\text { - feeling fatigued } \\
\text { - difficulty climbing stairs } \\
\text { - difficulty walking } 100 \mathrm{~m} \\
\text { - having } \geq 5 \text { chronic conditions }\end{array}$ & $\begin{array}{l}\text { Adherence to optimal therapy associated } \\
\text { with increased risk of falls with no } \\
\text { significant gain in cardiovascular health }\end{array}$ \\
\hline
\end{tabular}

Gnjidic et al. 2015*23 Community-dwelling men with ischaemic heart disease $(n=462,78$ years $)$
Presence of geriatric syndromes including frailty (defined using modified frailty phenotype)
Optimal therapy associated with lower risk of institutionalisation and mortality, stratified according to presence of geriatric syndromes including frailty

$\begin{array}{lll}\text { Poudel et al. } 2016^{* 8} & \text { Inpatients } & \text { Frailty index } \\ (\mathrm{n}=1418,81 \text { years }) & \end{array}$

Frail men more likely to be institutionalised or die than robust men, regardless of their statin use

Modified frailty phenotype

Risk of composite adverse outcome higher in frail patients with polypharmacy compared to robust patients with polypharmacy $(n=204,80.5$ years)
Risk of recurrent falls increased in frail patients taking 1.5 FRIDs and in robust patients taking 2.5 FRIDs

Reported Edmonton frail scale

Effects of intensive vs standard blood pressure treatment not significantly modified by frailty status

Antihypertensive treatment reduced risk of stroke, all-cause mortality or cardiovascular events in both frail and robust patients

\section{Frailty index}

Frailty index

\section{Warwick et al. 2015 $\left(\right.$ HYVET trial) ${ }^{\dagger 25}$ \\ Community-dwelling adults with hypertension ( $\mathrm{n}=2656$, indapamide \pm perindopril group: $83.6 \pm 3.2$ years, placebo group: 83.4 years)}

Community-dwelling adults with $(n=2510,79.9$ years $)$

* observational study

+ clinical trial

FRIDs falls-risk increasing drugs, refers to all drugs acting on the central nervous system or cardiovascular system (e.g. sleeping pills)

SPRINT Systolic Blood Pressure Intervention Trial

HYVET Hypertension in the Very Elderly Trial

\section{Drug interactions}

The prevalence of clinically relevant drug-drug interactions is higher in frail compared to robust inpatients. Our studies in a tertiary referral hospital identified more potential interactions in frail patients compared to robust patients ( $35 \%$ vs $5 \%$ ). ${ }^{7}$ Clinically relevant statin interactions were found in $9.5 \%$ of frail versus $6.8 \%$ of robust older inpatients. ${ }^{26}$

\section{Deprescribing}

Deprescribing is defined as withdrawing an inappropriate medicine, supervised by a healthcare professional, with the goal of managing polypharmacy and improving outcomes. . $^{27,28}$
In view of the limited evidence of benefit for medicines in frail older people and strong observational evidence of the increased risk of and from adverse drug events, trials of deprescribing have recently been conducted in frail older people. In a Western Australian study of people living in residential aged-care facilities, individualised medication reviews significantly reduced the number of regular medications by $2.0 \pm 0.9$ (95\% confidence interval 0.08-3.8, $p=0.04$ ) compared to the control group, with no significant change in clinical outcomes. ${ }^{29}$

Irish consensus criteria on drugs that are potentially inappropriate in frail older patients with limited life expectancy have recently been published. ${ }^{30}$ 
Known as 'STOPPFrail' (Screening Tool of Older Persons Prescriptions in Frail adults with limited life expectancy), they suggest deprescribing any medicine without a clear clinical indication or where compliance is poor, and include specific recommendations for 25 drug classes and indications.

\section{Tailoring therapy for frail older people}

When prescribing for older people, frailty status should be considered when applying the six steps in the World Health Organization's Guide to Good Prescribing. ${ }^{31}$ Medicines prescribed for chronic conditions need to be reviewed frequently to assess whether they are providing net benefit or net harm. Goals of care change frequently in frail people, and changes should prompt and inform re-evaluation of the patient's prescriptions. Opportunities to re-evaluate goals and treatment with patients and their families include acute admission to hospital, admission to a residential aged-care facility, and functional decline or a terminal illness such as the terminal phase of dementia.

\section{Step 1: Define the patient's problem}

Diagnoses can be difficult in frail older people as they often present with non-specific multifactorial geriatric syndromes such as falls, cognitive impairment and incontinence. Their presentation may also be affected by a reduced response to external stressors, for example they may not develop a fever or increased white cell count in response to an infection. Frailty may also impact on clinical decisions to conduct investigations. It is important to consider whether the patient's presentation is attributable to an adverse drug event as these are the most reversible causes of the geriatric syndromes. Also failure to recognise an adverse drug event could inadvertently result in a prescribing cascade. ${ }^{32}$

\section{Step 2: Specify the therapeutic objective}

The therapeutic objective refers to the desired pharmacodynamic effect of the drug. Frail older people are rarely represented in clinical trials, so there is limited evidence to support the efficacy and safety of most treatments for these patients. Often observational data or secondary analysis of clinical trial data can be used to inform therapeutic decisions (see Table 2). For example, in secondary prevention of cardiovascular disease, observational data suggest that optimal medical therapy (aspirin, ACE inhibitor, beta blocker and statin) reduce the risks of institutionalisation and mortality to a similar extent in older men with and without geriatric syndromes including frailty. ${ }^{23}$ There is also increasing evidence from subgroup analyses on the impact of polypharmacy on the safety and efficacy of drugs for specific disease states. ${ }^{33}$

\section{Step 3: Verify whether the treatment is suitable for the patient}

In people with multiple morbidities and disability, the benefit of the drug must be considered in view of the patient's other conditions, other medicines (and potential drug interactions) and global therapeutic objectives (goals of care). A full medication review is essential before starting a new medicine. For example, subgroup analysis of controlled trial data suggests that in frail older people intensive blood pressure control may reduce the risk of cardiovascular events, stroke and mortality. ${ }^{25}$ However, these outcomes may not be as high a priority for some frail older patients as reducing the risk of falls, which may increase with antihypertensives.

\section{Step 4: Start the treatment}

Discuss the therapeutic decision with the patient and their carers. Adjust the dose to account for the pharmacokinetic and pharmacodynamic changes of frailty (see Table 1). Use formulations that make administration simple. For example, use oncedaily slow-release formulations if the patient can swallow them.

\section{Step 5: Provide information, instructions and warnings}

It is important to give clear information verbally and in written form to the patient, their carers and other healthcare providers, including any specialists. An updated medication list is also important. Follow-up is important to ensure that the patient's plan has been communicated and is being implemented. Warnings should include adverse events seen commonly in frail older people that may not be prominent on standard consumer medicine information, such as the risks of falls, confusion, incontinence and polypharmacy.

\section{Step 6: Monitor (stop) the treatment}

Treatment can be stopped when the problem has been solved. In frail older people, 'solving' acute problems with medicines may involve completing a course of antimicrobials for an infection or analgesics for acute pain. If treatment for an acute or chronic problem is not effective, safe or convenient, it needs to be reviewed using the six steps again.

If a decision is made to stop a medicine, it is important to check whether it can be stopped suddenly or needs to be weaned gradually. ${ }^{34}$ It is important to monitor the outcomes of stopping treatment. These may include adverse drug withdrawal events, but more often than not there is no change or any adverse effects resolve quickly. 


\section{Conclusion}

Frail older people are major users of medicines, despite a paucity of evidence on pharmacokinetics and pharmacodynamics and decreased resilience to adverse drug events in this population. When prescribing it is essential to consider the patient's goals of care, function, comorbidities and overall medication load. Frequently review all medicines for frail older patients to ensure that they are receiving net benefit. Clinical trials (including deprescribing trials) and observational studies are starting to include objective measures of participants' frailty. This will help prescribers assess how the findings apply to frail and robust older patients in clinical practice. $<$

\section{Conflict of interest: none declared}

\section{REFERENCES}

1. Clegg A, Young J, lliffe S, Rikkert MO, Rockwood K. Frailty in elderly people Lancet 2013;381:752-62. https://doi.org/10.1016/S0140-6736(12)62167-9

2. Collard RM, Boter H, Schoevers RA, Oude Voshaar RC. Prevalence of frailty in community-dwelling older persons: a systematic review. J Am Geriatr Soc 2012;60:1487-92. https://doi.org/10.1111/j.1532-5415.2012.04054.x

3. Basic D, Shanley C. Frailty in an older inpatient population: using the clinical frailty scale to predict patient outcomes. J Aging Health 2015;27:670-85. https://doi.org/10.1177/0898264314558202

4. Kojima G. Prevalence of frailty in nursing homes: a systematic review and meta-analysis. J Am Med Dir Assoc 2015;16:940-5. https://doi.org/10.1016/ j.jamda.2015.06.025

5. Gnjidic D, Hilmer SN, Blyth FM, Naganathan V, Cumming RG, Handelsman DJ, et al. High risk prescribing and incidence of frailty among older communitydwelling men. Clin Pharmacol Ther 2012;91:521-8. https://doi.org/10.1038/ clpt.2011.258

6. Gnjidic D, Le Couteur DG, Blyth FM, Travison T, Rogers K, Naganathan V, et al. Statin use and clinical outcomes in older men: a prospective population-based study. BMJ Open 2013;3:e002333. https://doi.org/10.1136/ bmjopen-2012-002333

7. Bennett A, Gnjidic D, Gillett M, Carroll P, Matthews S, Johnell K, et al. Prevalence and impact of fall-risk-increasing drugs, polypharmacy, and drug-drug interactions in robust versus frail hospitalised falls patients: A Prospective Cohort Study. Drugs Aging 2014;31:225-32. https://doi.org/10.1007/ s40266-013-0151-3

8. Poudel A, Peel NM, Nissen LM, Mitchell CA, Gray LC, Hubbard RE. Adverse outcomes in relation to polypharmacy in robust and frail older hospital patients. J Am Med Dir Assoc 2016;17:767 e9-e13. https://doi.org/10.1016/ j.jamda.2016.05.017

9. Kane AE, Mitchell SJ, Mach J, Huizer-Pajkos A, McKenzie C, Jones B, et al. Acetaminophen hepatotoxicity in mice: Effect of age, frailty and exposure type. Exp Gerontol 2016;73:95-106. https://doi.org/10.1016/j.exger.2015.11.013

10. Hilmer SN, Tran K, Rubie P, Wright J, Gnjidic D, Mitchell SJ, et al. Gentamicin pharmacokinetics in old age and frailty. Br J Clin Pharmacol 2011;71:224-31. https://doi.org/10.1111/j.1365-2125.2010.03825.x

11. Schwartz JB. Erythromycin breath test results in elderly, very elderly, and frail elderly persons. Clin Pharmacol Ther 2006;79:440-8. https://doi.org/10.1016/ j.clpt.2006.01.006

12. Williams FM, Wynne H, Woodhouse KW, Rawlins MD. Plasma aspirin esterase: the influence of old age and frailty. Age Ageing 1989;18:39-42. https://doi.org/ 10.1093/ageing/18.1.39

13. Yelland C, Summerbell J, Nicholson E, Herd B, Wynne H, Woodhouse KW. The association of age with aspirin esterase activity in human liver. Age Ageing 1991;20:16-8. https://doi.org/10.1093/ageing/20.1.16

14. Wynne HA, Cope LH, Herd B, Rawlins MD, James OF, Woodhouse KW. The association of age and frailty with paracetamol conjugation in man Age Ageing 1990;19:419-24. https://doi.org/10.1093/ageing/19.6.419

15. Johnston C, Hilmer SN, McLachlan AJ, Matthews ST, Carroll PR, Kirkpatrick CM. The impact of frailty on pharmacokinetics in older people: using gentamicin population pharmacokinetic modeling to investigate changes in renal drug clearance by glomerular filtration. Eur J Clin Pharmacol 2014;70:549-55. https://doi.org/10.1007/s00228-014-1652-7

16. Wynne HA, Yelland C, Cope LH, Boddy A, Woodhouse KW, Bateman DN. The association of age and frailty with the pharmacokinetics and pharmacodynamics of metoclopramide. Age Ageing 1993;22:354-9. https://doi.org/10.1093/ageing/22.5.354

17. Nguyen TN, Morel-Kopp MC, Cumming R, Ward C, Hilmer S. Effect of frailty and age on platelet aggregation and response to aspirin in older patients with atrial fibrillation: a pilot study. Cardiol Ther 2016;5:51-62. https://doi.org/ 10.1007/s40119-016-0056-4

18. Cullinan S, O'Mahony D, O'Sullivan D, Byrne S. Use of a frailty index to identify potentially inappropriate prescribing and adverse drug reaction risks in older patients. Age Ageing 2016;45:115-20. https://doi.org/10.1093/ageing/afv166
19. Jamsen KM, Bell JS, Hilmer SN, Kirkpatrick CM, Ilomaki J, Le Couteur D, et al. Effects of changes in number of medications and drug burden index exposure on transitions between frailty states and death: The Concord Health and Ageing in Men Project Cohort Study. J Am Geriatr Soc 2016;64:89-95. https://doi.org/10.1111/jgs.13877

20. Gray SL, LaCroix AZ, Aragaki AK, McDermott M, Cochrane BB, Kooperberg CL, et al. Angiotensin-converting enzyme inhibitor use and incident frailty in women aged 65 and older: prospective findings from the Women's Health Initiative Observational Study. J Am Geriatr Soc 2009;57:297-303. https://doi.org/10.1111/j.1532-5415.2008.02121.x

21. LaCroix AZ, Gray SL, Aragaki A, Cochrane BB, Newman AB, Kooperberg CL, et al. Statin use and incident frailty in women aged 65 years or older: prospective findings from the Women's Health Initiative Observational Study. J Gerontol A Biol Sci Med Sci 2008;63:369-75. https://doi.org/10.1093/ gerona/63.4.369

22. Peeters G, Tett SE, Hollingworth SA, Gnjidic D, Hilmer SN, Dobson AJ, et al. Associations of guideline recommended medications for acute coronary syndromes with fall-related hospitalizations and cardiovascular events in older women with ischemic heart disease. J Gerontol A Biol Sci Med Sci 2017;72:259-65. https://doi.org/10.1093/gerona/glw111

23. Gnjidic D, Bennett A, Le Couteur DG, Blyth FM, Cumming RG, Waite L, et al. Ischemic heart disease, prescription of optimal medical therapy and geriatric syndromes in community-dwelling older men: a population-based study. Int J Cardiol 2015;192:49-55. https://doi.org/10.1016/j.ijcard.2015.05.045

24. Williamson JD, Supiano MA, Applegate WB, Berlowitz DR, Campbell RC Chertow GM, et al. Intensive vs standard blood pressure control and cardiovascular disease outcomes in adults aged $>/=75$ years: a randomized clinical trial. JAMA 2016;315:2673-82. https://doi.org/10.1001/jama.2016.7050

25. Warwick J, Falaschetti E, Rockwood K, Mitnitski A, Thijs L, Beckett N, et al. No evidence that frailty modifies the positive impact of antihypertensive treatment in very elderly people: an investigation of the impact of frailty upon treatment effect in the HYpertension in the Very Elderly Trial (HYVET) study, a double-blind, placebo-controlled study of antihypertensives in people with hypertension aged 80 and over. BMC Med 2015;13:78. https://doi.org/10.1186/ s12916-015-0328-1

26. Thai M, Hilmer S, Pearson SA, Reeve E, Gnjidic D. Prevalence of potential and clinically relevant statin-drug interactions in frail and robust older inpatients. Drugs Aging 2015;32:849-56. https://doi.org/10.1007/s40266-015-0302-9

27. Reeve $E$, Gnjidic D, Long J, Hilmer S. A systematic review of the emerging definition of 'deprescribing' with network analysis: implications for future research and clinical practice. Br J Clin Pharmacol 2015;80:1254-68. https://doi.org/10.1111/bcp.12732

28. Le Couteur D, Gnjidic D, McLachlan A. Deprescribing. Aust Prescr 2011;34:182-5 https://doi.org/10.18773/austprescr.2011.095

29. Potter K, Flicker L, Page A, Etherton-Beer C. Deprescribing in frail older people: a randomised controlled trial. PLoS One. 2016;11:e0149984. https://doi.org/10.1371/journal.pone.0149984

30. Lavan AH, Gallagher P, Parsons C, O’Mahony. STOPPFrail (Screening Tool of Older Persons Prescriptions in Frail Adults with Limited Life Expectancy): consensus validation. Age Ageing 2017 Jan 23 [Epub ahead of print]. https://doi.org/10.1093/ageing/afx005

31. de Vries TPGM, Henning RH, Hogerzeil HV, Fresle DA. Guide to good prescribing: a practical manual. Geneva: World Health Organization; 1994.

32. Kalisch LM, Caughey GE, Roughead EE, Gilbert AL. The prescribing cascade. Aust Prescr 2011;34:162-6. https://doi.org/10.18773/austprescr.2011.084

33. Jaspers Focks J, Brouwer MA, Wojdyla DM, Thomas L, Lopes RD, Washam JB, et al. Polypharmacy and effects of apixaban versus warfarin in patients with atrial fibrillation: post hoc analysis of the ARISTOTLE trial. BMJ 2016;353:i2868. https://doi.org/10.1136/bmj.i2868

34. Scott IA, Hilmer SN, Reeve E, Potter K, Le Couteur D, Rigby D, et al. Reducing inappropriate polypharmacy: the process of deprescribing. JAMA Intern Med 2015;175:827-34. https://doi.org/10.1001/jamainternmed.2015.0324 